\title{
Erratum to: The "sun-effect": microclimatic alterations predispose forest edges to bark beetle infestations
}

\author{
Markus Kautz $\cdot$ Reinhard Schopf $\cdot$ Joachim Ohser
}

Published online: 12 February 2013

(c) Springer-Verlag Berlin Heidelberg 2013

\section{Erratum to: Eur J Forest Res}

DOI 10.1007/s10342-013-0685-2

$F(r)=\frac{\mathbb{P}(\operatorname{dist}(x, A) \leq r \mid x \in B)}{\mathbb{P}(\operatorname{dist}(x, A) \leq r \mid x \in C)}, \quad r \geq 0$.

In addition to the above-mentioned error, the last matrix

Unfortunately, and beyond the authors' control, some errors crept in during the correction stage of the original publication. The most serious error is in the formula in the Materials and Methods section, following Fig. 3, where ' $\epsilon$ $B$ ' was omitted in the nominator of the following (correct) expression: in the same section was left with a confusing sequential number (3) at its bottom, right-hand side, and the caption to Fig. 4 should have included the indication "(Color figure online)'.

The online version of the original article can be found under doi: 10.1007/s10342-013-0685-2.

M. Kautz $(\bowtie) \cdot$ R. Schopf

Department of Ecology and Ecosystem Management, Institute of Animal Ecology, Technische Universität München,

Hans-Carl-von-Carlowitz-Platz 2, 85350 Freising, Germany

e-mail: kautz@wzw.tum.de

J. Ohser

Department of Mathematics and Natural Sciences,

Hochschule Darmstadt, Schöfferstr. 3, 64295 Darmstadt,

Germany 